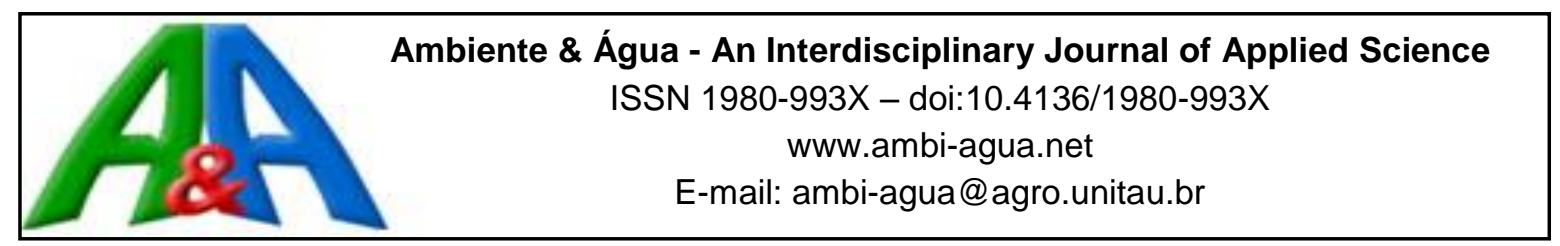

\title{
Influência das características morfométricas da bacia hidrográfica do rio Benevente nas enchentes no município de Alfredo Chaves-ES
}

\author{
doi: 10.4136/ambi-agua.1475 \\ Received: 01 Aug. 2014; Accepted: 07 Nov. 2014 \\ Alexandre Simões Lorenzon ${ }^{1 *}$; Micael de Souza Fraga ${ }^{2}$; \\ Amanda Rodrigues Moreira ${ }^{2}$; Eduardo Morgan Uliana ${ }^{2}$; \\ Demetrius David da Silva ${ }^{2}$; Carlos Antonio Alvares Soares Ribeiro ${ }^{1}$; \\ Alisson Carraro Borges ${ }^{2}$ \\ Universidade Federal de Viçosa (UFV), Viçosa, MG, Brasil \\ ${ }^{1}$ Departamento de Engenharia Florestal (DEF/UFV) \\ ${ }^{2}$ Departamento de Engenharia Agrícola (DEA/UFV) \\ *Autor correspondente: e-mail: alelorenzon@yahoo.com.br, \\ micaelfraga@yahoo.com.br, amanda.eaa2008@gmail.com, \\ morganuliana@gmail.com,demetrius@ufv.br, cribeiro@ufv.br, \\ borges@ufv.br
}

\section{RESUMO}

As enchentes afetam a vida de milhares de pessoas em todo o mundo e suas causas podem estar relacionadas tanto com fatores naturais como antrópicos. $\mathrm{O}$ objetivo do trabalho foi avaliar se a morfometria da bacia do rio Benevente tem relação com as enchentes ocorridas no município de Alfredo Chaves, ES. A base de dados consistiu de um modelo digital de elevação (ASTER), da rede hidrográfica vetorial do IBGE e de uma série histórica de 40 anos de precipitação diária. Os parâmetros morfométricos foram obtidos por meio de Sistemas de Informações Geográficas (SIG). A área de estudo possui uma forma alongada, relevo fortemente ondulado e declividade média da bacia de $42,75 \%$. A altitude variou de 480 a $1.591 \mathrm{~m}$. Novembro, dezembro e janeiro foram os meses de maior precipitação, com média mensal de 246,7, 261,5 e 204,2 mm, respectivamente. Conclui-se que a alta declividade da bacia e do rio principal, aliada à intensificação do uso e ocupação do solo, exerce expressiva influência sobre o escoamento superficial na bacia, aumentando as chances de ocorrência de picos de enchentes.

Palavras-chave: gestão de recursos hídricos, hidrologia, morfometria.

\section{Influence of morphometric characteristics of the Benevente River watershed in Alfredo Chaves Municipality - Espírito Santo State}

\begin{abstract}
Floods affect the lives of thousands of people around the world and their causes may be related to both natural and anthropogenic factors. The objective of this study was to evaluate the relationship between the Benevente River watershed morphometry and the occurrence of floods in the town of Alfredo Chaves, Espírito Santo State, Brazil. The database consisted of a digital elevation model (ASTER), a vector hydrographic network of IBGE and a 40-year
\end{abstract}


period series of daily precipitation. The morphometric parameters were obtained using Geographic Information Systems (GIS). The study area has an elongated shape, with a high drainage density, strongly undulate topography and an average slope of $42.75 \%$. The altitude ranged from 480 to $1591 \mathrm{~m}$. November, December and January were the wettest months, with a monthly average rainfall of 246.7, 261.5 and $204.2 \mathrm{~mm}$, respectively. It was concluded that high slopes of the basin and of the main river, coupled with increased use and occupation of the land, exerts significant influence on the runoff in the basin, increasing the chances of the occurrence of flood peaks.

Keywords: hydrology, morphometry, water resources management.

\section{INTRODUÇÃO}

Dentre os inúmeros fenômenos naturais, as enchentes afetam a vida de 102 milhões de pessoas a cada ano no mundo (UN, 2012). A maior parte da população atingida encontra-se em espaços geográficos vulneráveis, normalmente, próximo a cursos d'água. Suas causas, bem como as respostas e as ações para prevenção e mitigação, é tema de grande interesse público após inúmeros eventos de chuva resultar em perdas de âmbito econômico, ambiental e social (Freitas e Ximenes, 2012).

Segundo Tucci (2001), a ocorrência das enchentes pode estar relacionada tanto com fatores naturais como antrópicos. As condições naturais são aquelas cujas ocorrências são causadas pela bacia em seu estado natural, como: relevo, cobertura vegetal, capacidade de drenagem, forma da bacia e intensidade, duração e frequência das precipitações. As condições antrópicas são aquelas provocadas pela ação do homem, como: urbanização, obras hidráulicas, desmatamento, manejo inadequado do solo, entre outras.

O processo de ocupação e desenvolvimento da sociedade, seja na área urbana ou rural, tem gerado uma intensa degradação do ambiente (Carvalho et al., 2012), que ao longo do tempo tem contribuído, consideravelmente, para maior frequência e magnitude das enchentes (Righi e Robaina, 2010).

As bacias hidrográficas integram uma visão conjunta do comportamento das condições naturais, das atividades humanas e das mudanças nelas desenvolvidas (Guerra e Cunha, 2003). O conhecimento das características morfométricas de uma bacia hidrográfica é imprescindível para a conservação dos recursos hídricos, pois torna possível a compreensão do comportamento hidrológico e possibilita acompanhar as interferências nos processos do ciclo hidrológico e as respectivas respostas da natureza (Ferreira et al, 2012). Desta forma, o conhecimento das características morfométricas pode garantir maior eficiência das intervenções que venham a ser realizadas na bacia, facilitando o seu planejamento, de modo a minimizar impactos ambientais e desastres naturais (Carelli e Lopes, 2011).

O município de Alfredo Chaves é frequentemente atingido pelas enchentes do rio Benevente. No ano de 2012, o município sofreu a pior inundação de sua história, a chuva fez o rio Benevente transbordar e subir mais de 10 metros, alagando mais de $80 \%$ das ruas da cidade. Muitos moradores perderam casas, assim como destruição de lavouras, estradas e pontes (Huber, 2012; Scalzer, 2013).

Nesse contexto, o objetivo do trabalho foi realizar a caracterização morfométrica da bacia hidrográfica do rio Benevente, a montante da estação fluviométrica Matilde (código 57250000), com a finalidade de verificar a relação dos parâmetros físicos e climáticos da bacia com as enchentes ocorridas no município de Alfredo Chaves. 


\section{MATERIAL E MÉTODOS}

\section{1. Área de estudo}

A área de estudo compreende a bacia hidrográfica do rio Benevente (Figura 1), a montante da estação fluviométrica Matilde (código 57250000) pertencente à rede hidrometeorológica da Agência Nacional de Águas (ANA), localizada no município de Alfredo Chaves, a $88 \mathrm{~km}$ da capital do Estado do Espírito Santo.

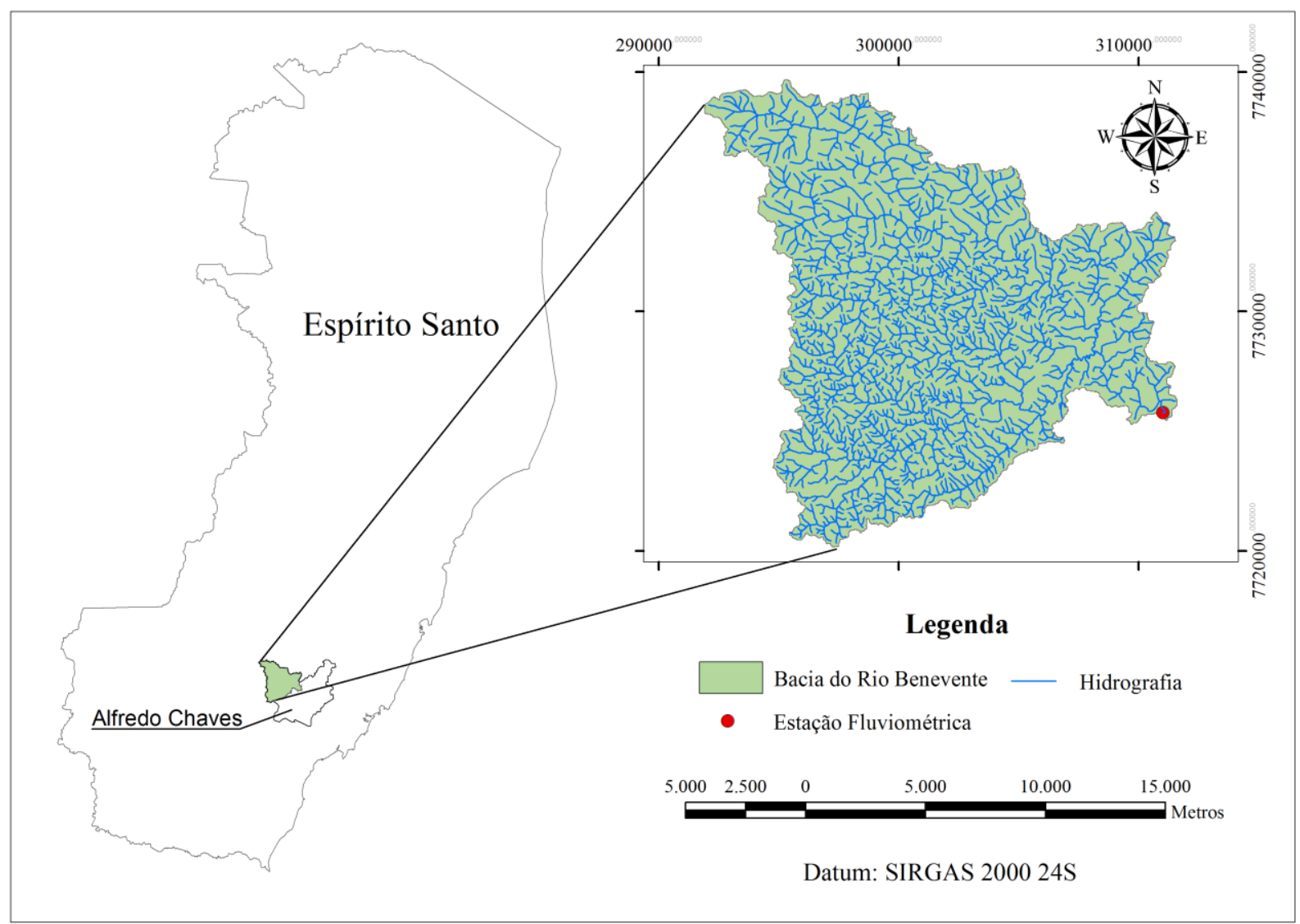

Figura 1. Localização da bacia hidrográfica do rio Benevente, Alfredo Chaves-ES.

A cabeceira da área de drenagem que forma a nascente do rio Benevente encontra-se na Serra do Tamanco, Distrito de São Bento de Urânia. O rio percorre cerca de $79 \mathrm{~km}$ até sua foz no município de Anchieta. Seus principais afluentes são os rios Batatal, Caco do Pote, Corindiba, Conceição, Crubixá, Grande, Iriritimirim, Joeba, Maravilha, Pongal, Salinas e São Joaquim (Espírito Santo, 2013).

Segundo a classificação climática de Köppen, o clima da região é classificado como tropical úmido com estação seca de inverno (Aw). A precipitação média anual e a umidade relativa são iguais a $1.566 \mathrm{~mm}$ e $83 \%$, respectivamente, sendo a temperatura média anual igual a $22{ }^{\circ} \mathrm{C}$.

O município de Alfredo Chaves possui um relevo montanhoso com picos e vales, tais como: Pico do Tamanco, Pico do Gururu, Salto D’água, Serra Pão Doce, Serra do Batatal, Serra Richmont e Serra Boa Vista. Os solos predominantes da região são os classificados como Latossolo Vermelho Amarelo Distrófico, com fertilidade variando de média a baixa e pH moderadamente ácido em torno de 5,0 (Alfredo Chaves, 2013).

As principais atividades econômicas desenvolvidas no município são a agricultura, com destaque para a cultura do café, banana e inhame, a pecuária e o turismo, em virtude do rico potencial de atrativos naturais (Alfredo Chaves, 2013). 


\subsection{Modelo Digital de Elevação (MDE)}

Utilizou-se o Modelo Digital de Elevação (MDE) Advanced Spaceborne Thermal Emission and Reflection Radiometer Global Digital Elevation Model (ASTERGDEM), com resolução espacial de $30 \mathrm{~m}$. Originalmente, esse modelo possui sistema de coordenadas geográficas e datum WGS84. Procedeu-se, então, à conversão do sistema de projeção para UTM e Datum SIRGAS 2000, fuso 24S. O software utilizado para manipulação dos dados foi o ArcGIS 10.1/ArcMap® do ESRI.

Segundo Ribeiro et al. (2002), a maioria dos modelos digitais de elevação possuem irregularidades que inviabilizam a correta delimitação da área de contribuição a montante do ponto de interesse, comprometendo seu uso para estudos hidrológicos. Assim, segundo metodologia descrita em Elesbon et al. (2011), foram realizadas operações de pós-processamento com a finalidade de eliminar essas imperfeições e gerar o Modelo Digital de Elevação Hidrograficamente Condicionado (MDEHC), objetivando garantir a convergência do escoamento superficial até a foz da bacia.

\subsection{Precipitação}

Foram utilizados dados de precipitações diárias da estação pluviométrica Matilde (código 02040011), pertencente à rede hidrometeorológica da Agência Nacional de Águas (ANA). As observações foram de uma série histórica de 40 anos (período-base de 1976 até 2013, exceto 1989 pela falta de informação). Para análise de consistência dos dados, utilizou-se o software Hidro 1.2.1 para gerar uma base de dados para o programa Hidro-Plu Beta 4.1.

\subsection{Características morfométricas}

A obtenção das características morfométricas também foi realizada em ambiente de SIG, utilizando o software ArcGIS 10.1/ArcMap® do ESRI.

\subsection{1. Área de drenagem e perímetro}

Utilizou-se o comando watershed da extensão Spatial Analyst, disponível na interface ArcToolbox, para delimitar a bacia de contribuição, considerando o MDEHC e um arquivo contendo a localização do exutório da mesma. Uma vez delimitada a bacia, a área de drenagem e o perímetro foram gerados automaticamente pelo software.

\subsubsection{Comprimento do rio}

$\mathrm{Na}$ determinação desse parâmetro utilizou-se a malha hidrográfica da bacia do rio Benevente obtida da base de dados digital do IBGE na escala 1:50.000. De posse da hidrografia, foi mensurado o comprimento total dos cursos d'água e o comprimento do rio principal. Este foi considerado como aquele que apresenta maior área de drenagem.

\subsubsection{Ordem dos cursos d'água}

Para a hierarquização dos cursos d'água, foi utilizado o método proposto por Strahler (1957), sendo esse o mais utilizado por possuir melhor compreensão (Oliveira e Borsato, 2011). Para classificar os cursos d'água por este método foi utilizado o comando Stream Order da extensão Spatial Analyst, disponível na interface ArcToolbox.

\subsubsection{Densidade de drenagem}

O sistema de drenagem é formado pelo rio principal e seus tributários ou afluentes e indica a maior ou menor ramificação da rede de drenagem na bacia hidrográfica, fornecendo uma indicação da eficiência da drenagem da bacia (Cardoso et al., 2006). A densidade de drenagem foi calculada de acordo com a Equação 1. 


$$
D d=\frac{L_{t}}{A}
$$

em que:

Dd $=$ densidade de drenagem $\left(\mathrm{km} \mathrm{km}^{-2}\right)$,

$\mathrm{Lt}=$ comprimento total dos cursos d'água $(\mathrm{km})$, e

$\mathrm{A}=$ área de drenagem $\left(\mathrm{km}^{2}\right)$.

\subsubsection{Declividade da bacia e altitude}

A partir do MDEHC, foi gerado um mapa de declividade utilizando-se o comando Slope disponível na extensão Spatial Analist da interface ArcToolbox. Em seguida, foi feita uma reclassificação das classes de valores de declividade em seis intervalos distintos, conforme proposto por Embrapa (1979). Para isso, utilizou-se o comando Reclassify da extensão Spatial Analyst. Uma vez gerado o mapa de declividade, o software automaticamente determina alguns parâmetros relativos ao mesmo, entre estes, a declividade média. Os valores de altitude foram obtidos diretamente do MDEHC.

\subsubsection{Fator de forma}

Obteve-se o fator de forma por meio da relação entre a área e o comprimento axial da bacia (Equação 2).

$$
K f=\frac{A}{L^{2}}
$$

em que:

$$
\begin{aligned}
& \mathrm{Kf}=\text { fator de forma (adimensional), } \\
& \mathrm{A}=\text { área de drenagem }\left(\mathrm{L}^{2}\right), \mathrm{e} \\
& \mathrm{L}=\text { comprimento axial da bacia }(\mathrm{L}) .
\end{aligned}
$$

\subsubsection{Coeficiente de compacidade}

O coeficiente de compacidade foi obtido por meio da relação entre o perímetro e a área da bacia (Carvalho et al., 2009), conforme a Equação 3.

$$
K c=0,28 \frac{P}{\sqrt{A}}
$$

em que:

Kc $=$ coeficiente de compacidade,

$\mathrm{P}=$ perímetro $(\mathrm{L}), \mathrm{e}$

$\mathrm{A}=$ área de drenagem $\left(\mathrm{L}^{2}\right)$.

\subsection{8. Índice de circularidade}

Similarmente ao coeficiente de compacidade, o índice de circularidade tende para a unidade à medida que a bacia se aproxima da forma circular (Cardoso et al., 2006). Este índice é calculado de acordo coma Equação 4. 


$$
I C=\frac{12,57 A}{P^{2}}
$$

em que:

$$
\begin{aligned}
& \mathrm{IC}=\text { índice de circularidade, } \\
& \mathrm{A}=\text { área de drenagem }\left(\mathrm{L}^{2}\right), \mathrm{e} \\
& \mathrm{P}=\text { perímetro }(\mathrm{L}) .
\end{aligned}
$$

\subsubsection{Tempo de concentração}

Para determinar o tempo de concentração foi utilizada equação de Giandotti (Pruski et al., 2004), conforme Equação 5.

$$
t c=\frac{4 \sqrt{A}+1,5 L}{0,8 \sqrt{H}}
$$

em que:

$$
\begin{aligned}
& \text { tc }=\text { tempo de concentração }(\mathrm{h}), \\
& \mathrm{A}=\text { área da bacia }\left(\mathrm{km}^{2}\right), \\
& \mathrm{L}=\text { comprimento do talvegue }(\mathrm{km}) \mathrm{e} \\
& \mathrm{H}=\text { diferença de nível entre o ponto mais remoto da bacia e a seção de deságue }(\mathrm{m}) .
\end{aligned}
$$

\subsubsection{Declividade do rio principal}

Para o cálculo da declividade do rio principal foi levado em consideração o tempo de percurso da água ao longo da extensão do perfil longitudinal, obtendo-se a declividade equivalente constante (Villela e Mattos, 1975), como pode ser visto na Equação 6.

$$
S=\left(\frac{\sum L_{i}}{\sum\left(\frac{L_{i}}{\sqrt{D_{i}}}\right)}\right)^{2}
$$

em que:

$\mathrm{S}=$ declividade equivalente $\left(\mathrm{m} \mathrm{m}^{-1}\right)$,

$\mathrm{Li}=$ distância em cada trecho considerado $(\mathrm{m}) \mathrm{e}$

$\mathrm{Di}=$ declividade em cada trecho considerado $\left(\mathrm{m} \mathrm{m}^{-1}\right)$.

\section{RESULTADOS E DISCUSSÃO}

Na Tabela 1 são apresentados os parâmetros morfométricos obtidos pelo estudo. 
Tabela 1. Características morfométricas da bacia hidrográfica do rio Benevente, Alfredo Chaves-ES, Brasil.

\begin{tabular}{lc}
\hline Características morfométricas & Resultados \\
\hline Área de drenagem $\left(\mathrm{km}^{2}\right)$ & 210,49 \\
Perímetro $(\mathrm{km})$ & 121,70 \\
Comprimento do rio principal $(\mathrm{km})$ & 35,15 \\
Declividade do rio principal $(\%)$ & 1,69 \\
Comprimento total dos cursos d'água $(\mathrm{km})$ & 768,86 \\
Ordem da bacia & 6 \\
Densidade de drenagem (km km $)$ & 3,65 \\
Declividade média (\%) & 42,75 \\
Altitude máxima (m) & 1591,00 \\
Altitude média (m) & 903,21 \\
Altitude mínima (m) & 480,00 \\
Fator de forma & 0,17 \\
Coeficiente de compacidade & 2,35 \\
Índice de circularidade & 0,18 \\
Tempo de concentração (h) & 4,68 \\
\hline
\end{tabular}

$\mathrm{O}$ fator de forma e o índice de circularidade apresentaram resultados muito baixos. Esses valores indicam que a bacia possui uma forma mais alongada. Ademais, o coeficiente de compacidade foi alto, sendo este um número adimensional que varia com a forma da bacia, independentemente do seu tamanho (Villela e Mattos, 1975). Quanto mais a forma da bacia se distancia do formato circular, maior deverá ser este índice. Analisando-se isoladamente esses resultados, pode-se inferir, pela forma da bacia, que a área de estudo é menos propensa à ocorrência de enchentes em condições normais de precipitação. Segundo Cardoso et al. (2006), as bacias com forma alongada possuem baixa probabilidade de chuvas intensas ocorrerem simultaneamente em toda a sua extensão. Além disso, quanto mais irregular for a forma da bacia maior será o coeficiente de compacidade e menor a tendência para enchentes em condições normais de precipitação. Destaca-se, entretanto, que não se pode avaliar a propensão às enchentes em uma bacia com base exclusivamente na sua forma.

A forma da bacia hidrográfica também influencia o tempo de concentração, ou seja, o tempo necessário para que toda a bacia contribua para a saída da água após uma precipitação (Tonello et al., 2006). Nas bacias alongadas, os afluentes atingem o curso d'água principal em vários pontos ao longo do mesmo, diferentemente das bacias circulares, na qual a concentração do deflúvio se dá em um só ponto diminuindo o tempo de concentração e aumentando as chances de ocorrência de enchentes (Villela e Mattos, 1975). Por isso, o tempo de concentração foi alto para a área de estudo, sendo este um reflexo da forma alongada da bacia.

Apesar da forma alongada, a bacia tem sofrido com constantes enchentes que atingem o município quase todos os anos. O estado do Espírito Santo possui dois períodos de precipitação bem distintos, um chuvoso, entre outubro e março (verão), e outro mais seco, com totais médios mensais inferiores a $30 \mathrm{~mm}$, entre abril e setembro (inverno) (De Mello 
et al., 2012). Os autores supracitados verificaram também que a região de Alfredo Chaves possui uma precipitação média mensal maior que as demais regiões do Estado.

Pela análise dos dados da estação pluviométrica utilizada no estudo verifica-se que o período de chuvas concentrou-se entre outubro e março no município de Alfredo Chaves. Os meses de novembro, dezembro e janeiro apresentaram um período contínuo de muita chuva, com média histórica que varia de 204,2 a 261,5 mm (Tabela 2).

Tabela 2. Precipitação média mensal dos seis meses mais chuvosos no município de Alfredo Chaves-ES, Brasil.

\begin{tabular}{lc}
\hline \multicolumn{1}{c}{ Mês } & Média $(\mathbf{m m})$ \\
\hline Outubro & 148,8 \\
Novembro & 246,7 \\
Dezembro & 261,5 \\
Janeiro & 204,2 \\
Fevereiro & 120,9 \\
Março & 221,6 \\
\hline
\end{tabular}

Segundo Reboita et al. (2010) e De Mello et al. (2012), a estação chuvosa do sudeste do Brasil é causada pela zona de convergência do atlântico sul, a qual é a principal causadora de precipitações que ocorrem especialmente entre novembro e janeiro, transportando calor e umidade do oceano atlântico para o interior do Brasil. Esses fatores climáticos, associados à ocorrência de serras e picos do município de Alfredo Chaves, com altitudes que chegam a $1.591 \mathrm{~m}$, estabelecem condições apropriadas para a formação de chuvas orográficas, as quais apresentam alto potencial para causar enchentes devido à sua curta duração e alta intensidade.

As chuvas orográficas são causadas pela ascensão do ar úmido e quente sobre regiões que apresentam elevada variação de altitude (Silva et al., 2012). Esse fenômeno atmosférico foi observado por Kruk et al. (2006), na Serra do Mar no Estado de São Paulo e por Silva et al. (2012), na Serra do Mar no Estado do Paraná. Esses autores destacam ainda a influência da zona de convergência do atlântico sul nas chuvas orográficas ocorridas nessas regiões.

A declividade da bacia e do rio principal são outros fatores com relevante influência nas enchentes que ocorrem no município de Alfredo Chaves. A área de estudo apresentou elevada variação de altitude, com valores entre 480 e $1.591 \mathrm{~m}$ (Tabela 1). Por isso, a declividade média foi alta e o relevo classificado como fortemente ondulado (EMBRAPA, 1979). As áreas planas ( 0 a $3 \%$ ) ocupam apenas $1,24 \%$ da área total da bacia, enquanto que as áreas com relevo mais acentuado ( $>45 \%$ ) ocupam quase que a metade da bacia, $42,47 \%$. Observa-se, ainda, que $74,01 \%$ da área correspondem ao relevo fortemente ondulado e montanhoso (Tabela 3).

Tabela 3. Distribuição das classes de declividade da bacia hidrográfica do rio Benevente, Alfredo Chaves-ES, Brasil, segundo Embrapa (1979).

\begin{tabular}{clcc}
\hline Declividade (\%) & \multicolumn{1}{c}{ Relevo } & Área $\left.\mathbf{( k m}^{2}\right)$ & Área $(\%)$ \\
\hline $0-3$ & Plano & 2,61 & 1,24 \\
$3-8$ & Suavemente ondulado & 5,82 & 2,76 \\
$8-20$ & Ondulado & 26,94 & 12,80 \\
$20-45$ & Fortemente ondulado & 85,74 & 40,73 \\
$45-75$ & Montanhoso & 70,03 & 33,28 \\
$>75$ & Fortemente & 19,35 & 9,19 \\
\hline
\end{tabular}


Em áreas com declividade acentuada, a água da chuva concentra-se mais rapidamente nos cursos dos rios aumentando as chances de ocorrer picos de enchentes. A declividade afeta a velocidade do escoamento superficial, diminui a infiltração da água da chuva (Cardoso et al., 2006; Tonello et al., 2006) e potencializa o processo erosivo do solo (Pissarra et al., 2010; Santos et al., 2012). De acordo com Calil et al. (2012), em locais de chuvas intensas, onde a infiltração é dificultada por altas declividades, ocorre maior ramificação da rede hidrográfica, cuja consequência são bacias com densidade de drenagem mais alta e escoamento superficial mais eficiente.

Segundo Villela e Mattos (1975), a densidade de drenagem fornece a eficiência de drenagem da bacia. Para os autores supracitados esse índice pode variar de $0,5 \mathrm{~km} \mathrm{~km}^{-2} \mathrm{em}$ bacias com drenagem pobre, a $3,5 \mathrm{~km} \mathrm{~km}^{-2}$ ou mais, para bacias bem drenadas, considerando a escala de 1:50.000. Para a bacia em estudo, a densidade de drenagem e o comprimento total dos cursos d'água apresentaram valores bem elevados, caracterizando a bacia como bem drenada (Tabela 1). Confirmando esta tendência, a bacia apresentou grau de ramificação de sexta ordem pela hierarquização de Strahler (1957).

Outra característica morfométrica muito importante para fins de análise da propensão à ocorrência de enchentes é a declividade do rio principal, que no caso em questão foi de $1,69 \%$, valor extremamente elevado para canais naturais e, certamente, um dos principais responsáveis pelos picos de enchentes na bacia do rio Benevente.

A magnitude dos picos de enchentes pode ainda ser intensificada quando altas declividades estão relacionadas com a ausência de cobertura vegetal, tipo de solo e intensidade de precipitação, uma vez que esses fatores aumentam a rapidez com que ocorre o escoamento superficial no terreno (Villela e Mattos, 1975; Tonello et al., 2006).

Segundo Soprani e Reis (2007), dentre os principais problemas da região de Alfredo Chaves, destacam-se o acelerado processo de ocupação do solo, nascentes e cursos d'água desprovidos de mata ciliar, processos erosivos decorrentes do uso de encostas para plantio, lançamentos de efluentes e resíduos sólidos nos cursos d'água.

\section{CONCLUSÕES}

Conclui-se que, dentre as características morfométricas avaliadas, os elevados valores de declividade do rio principal e de declividade da bacia, decorrentes da grande variação de altitude na bacia do rio Benevente, assim como dos expressivos valores de densidade de drenagem, são os principais causadores das enchentes do município de Alfredo Chaves. Destaca-se, ainda, que na região ocorrem maiores índices pluviométricos do que em outras regiões do estado, decorrente da maior propensão à ocorrência de chuvas orográficas, potencializando ainda mais a ocorrência do escoamento superficial e, consequentemente, os picos de enchentes.

\section{REFERENCIAS}

ALFREDO CHAVES. Prefeitura. Disponível em: <www.alfredochaves.es.gov.br>. Acesso em: 25 set. 2013.

CALIL, P. M.; OliVEIRA, L. F. C. de; KLIEMANN, H. J.; OLIVEIRA, V. A. de. Caracterização geomorfométrica e do uso do solo da bacia hidrográfica do Alto Meia Ponte, Goiás. Revista Brasileira de Engenharia Agrícola e Ambiental, Campina Grande, v. 16, n. 4, p. 433-442, 2012. http://dx.doi.org/10.1590/S141543662012000400014 
CARDOSO, C. A.; DIAS, H. C. T; SOARES, C. P. B.; MARTINS, S. V. Caracterização morfométrica da bacia hidrográfica do Rio Debossan, Nova Friburgo, RJ. Revista Árvore, Viçosa, v. 30, n.2, p. 241-248, 2006. http://dx.doi.org/10.1590/S010067622006000200011

CARELLI, L.; LOPES, P. P. Caracterização fisiográfica da bacia Olhos D’água em Feira de Santana/BA: Geoprocessamento aplicado à análise ambiental. Boletim Goiano de Geografia, Goiânia, v. 31, n. 2, p. 43-54, 2011.

CARVALHO, A. P. V.; BRUMATTI, D. V.; DIAS, H. C. T. Importância do manejo da bacia hidrográfica e da determinação de processos hidrológicos. Revista Brasileira de Agropecuária Sustentável, Viçosa, v. 2, n. 2, p. 148-156, 2012.

CARVAlHO, W. M.; VIEIRA, E. O.; ROCHA, J. M. J.; PEREIRA, A. K. S.; CARMO, T. V. B. do. Caracterização fisiográfica da bacia hidrográfica do Córrego do Malheiro, no município de Sabará-MG. Irriga, Botucatu, v. 14, n. 3, p. 389-412, 2009.

DE MELLO, C. R.; VIOLA, M. R; CURI, N.; SILVA, A. M. da. Distribuição espacial da precipitação e da erosividade da chuva mensal e anual no estado do Espírito Santo. Revista Brasileira de Ciência do Solo, Viçosa, v. 36, p. 1878-1891, 2012. http://dx.doi.org/10.1590/S0100-06832012000600022

ELESBON, A. A. A.; GUEDES, H. A. S.; DA SILVA, D. D.; OLIVEIRA, I. C. Uso de dados SRTM e plataforma SIG na caracterização morfométrica da bacia hidrográfica do Braço Norte do Rio São Mateus - Brasil. Revista Escola de Minas, Ouro Preto, v. 64, n. 3, p. 281-288, 2011.

EMPRESA BRASILEIRA DE PESQUISA AGROPECUÁRIA - EMBRAPA. Serviço nacional de levantamento e conservação de solos. In: REUNIÃO TÉCNICA DE LEVANTAMENTO DE SOLOS, 10., 1979, Rio de Janeiro. Súmula... Rio de Janeiro: EMBRAPA; SNLCS, 1979. 83 p.

ESPÍRITO SANTO. Secretaria de Estado de Meio Ambiente e Recursos Hídricos - SEAMA. Website. Disponível em: <www.meioambiente.es.gov.br>. Acesso em: 30 jun. 2013.

FERREIRA, R. G.; MOURA, M. C. O.; CASTRO, F. S. Caracterização morfométrica da subbacia do Ribeirão Panquinhas, ES. Enciclopédia Biosfera, Goiânia, v. 8, n. 15, p. 2247 2256, 2012.

FREITAS, C. M; XIMENES, E. F. Enchentes e saúde pública - uma questão na literatura científica recente das causas, consequências e respostas para prevenção e mitigação. Ciência \& Saúde Coletiva, Rio de Janeiro, v. 17, n. 6, p. 1601-1615, 2012. http://dx.doi.org/10.1590/S1413-81232012000600023

GUERRA, A. J. T.; CUNHA, S. B. Geomorfologia e meio ambiente. 4. ed. Rio de Janeiro: Bertrand Brasil, 2003. 394 p.

HUBER, J. Alfredo Chaves sofreu a pior enchente de sua história. Montanhas Capixabas, Alfredo Chaves, 2012. Disponível em: <www.montanhascapixabas.com.br/?x=materia \&codItem=5503\&codArea=1 >. Acesso em: 30 jan. 2014.

KRUK, N. S.; HOFFMANN, P.; RAABE, A. Modeling of orographic precipitation events in South America to couple hydrological and atmospheric models. Part I: The simulation of rain with the Mesoscale Model GESIMA. Wissenschaftliche Mitteilungen Aus Dem Institut Für Meteorologie Der Universität Leipzig, v. 37, p. 137-147, 2006. 
OLIVEIRA, E. D.; BORSATO, V. A. Propriedades morfométricas da bacia hidrográfica do Córrego Marumbizinho, Jandaia do Sul/PR. Revista Geografar, Curitiba, v. 6, n. 1, p. 76-94, 2011.

PISSARRA, T. C. T.; RODRIGUES, F. M.; POLITANO, W.; GAlBiATTI, J. A. Morfometria de microbacias do Córrego Rico, afluente do Rio Mogi-Guaçu, Estado de São Paulo, Brasil. Revista Árvore, Viçosa, v. 34, n. 4, p. 669-676, 2010. http://dx.doi.org/10.1590/S0100-67622010000400011

PRUSKI, F. F.; BRANDÃO, V. D. S.; SILVA, D. D. D. Escoamento superficial. 2. ed. Viçosa: Editora UFV, 2004. 87 p.

REBOITA, M. S.; GAN, M. A.; ROCHA, R. P.; AMBRIZZI, T. Regimes de precipitação na América do Sul: uma revisão bibliográfica. Revista Brasileira de Meteorologia, São José dos Campos, v. 25, n. 2, p. 185-204, 2010.

RIBEIRO, C. A. A. S.; CHAVES, M. A.; SOARES, V. P.; EUCLYDES, H. P. Modelos digitais de elevação hidrologicamente consistentes para a Amazônia legal. In: SIMPÓSIO DE RECURSOS HÍDRICOS DO CENTRO-OESTE, 2., 2002, Campo Grande. Anais... Campo Grande: ABRH, 2002.

RIGHI, E.; ROBAINA, L. E. S. Enchentes do Rio Uruguai no Rio Grande do Sul entre 1980 e 2005: uma análise geográfica. Sociedade \& Natureza, Uberlândia, v. 22, n. 1, p. 35-54, 2010. http://dx.doi.org/10.1590/S1982-45132010000100004

SANTOS, D. B.; VIDOTTO, M. L.; BERTINATTO, R.; MARCON, G. R. S.; FRIGO, E. P. Caracterização morfométrica da bacia hidrográfica do Rio São José, Cascavel, PR. Revista Brasileira de Tecnologia Aplicada nas Ciências Agrárias, Guarapuava, v. 5, n. 2, p. 7-18, 2012.

SCALZER, P. Um ano depois, lembranças da grande enchente ainda atormentam moradores. CBN Vitória, Vitória, 2013. Disponível em: <http://gazetaonline.globo.com/_conteudo/ 2013/10/cbn_vitoria/reportagens/1464907-um-ano-depois-lembrancas-da-grandeenchente-ainda-atormentam-moradores.html>. Acesso em: 30 jan. 2014.

SILVA, A. M. A.; OLIVEIRA, A. G.; LOEZER, T. L.; SOUZA, R. M.Avaliação do comportamento da precipitação entre o primeiro planalto paranaense e o litoral do Paraná no ano hidrológico 2010/2011. Revista Geonorte, Manaus, v. 2, n. 5, p. 967974, 2012.

SOPRANI, M. A; REIS, J. A. T. Proposição de equações de intensidade-duração-frequência de precipitações para a bacia do Rio Benevente, ES. Revista Capixaba de Ciência e Tecnologia, Vitória, v. 2, n. 1, p. 18-25, 2007.

STRAHLER, A. N. Quantitative analysis of watershed Geomorphology.Transactions. American Geophysical Union, v. 38, n. 6, p. 913-920, 1957.

TONELlO, K. C.; DIAS, H. C. T.; SOUZA, A. L.; RIBEIRO, C. A. A. S.; LEITE, F. P. Morfometria da bacia hidrográfica da Cachoeira das Pombas, Guanhães - MG. Revista Árvore, Viçosa, v. 30, n. 5, p. 849-857, 2006. http://dx.doi.org/10.1590/S010067622006000500019

TUCCI, C. E. M. Hidrologia: ciência e aplicação. 2. ed. Porto Alegre: UFRGS; Edusp; ABRH, 2001. 943 p. 
VILLELA, S. M; MATTOS, A. Hidrologia aplicada. São Paulo: McGraw-Hill do Brasil, 1975. $245 \mathrm{p}$.

UNITED NATIONS-UN. Disaster-resilient Societies - Facts and figures. 2012. Disponível em: <www.un.org/en/sustainablefuture/disasters.shtml〉. Acesso em: 22 jan. 2014. 